Research Journal of Applied Sciences 6 (6): 387-390, 2011

ISSN: $1815-932 \mathrm{X}$

(C) Medwell Journals, 2011

\title{
Modeling of Simply Supported Steel Bars under Central Concentrated Static Load
}

\author{
Naim Syla and Fisnik Aliaj \\ Department of Physics, Faculty of Natural Sciences, University of Prishtina, \\ Mother Theresa St. 5, 10000 Prishtina, Republic of Kosovo
}

\begin{abstract}
Finite element method was used to model simply supported steel bars under a central concentrated static load. Software of choice to implement the method was ANSYS. The results of the model were compared with the elementary beam theory and laboratory investigations performed with simple university-level equipment. The computer model gave similar results to the real behavior. The moduli of elasticity calculated from experimental data were within $8 \%$ of the value given in literature.
\end{abstract}

Key words: Finite element method, beams, deflection, ANSYS, beam theory, Kosovo

\section{INTRODUCTION}

Beams are important fundamental structural and/or machine elements; they are found in buildings and in bridges. Beams are also used as shafts in cars and trains as wings in aircrafts and bookshelves in bookstores. Arms and femurs of human beings and branches of trees are good examples of portions of living creatures which support their bodies. Beams play important roles not only in organic but also in inorganic structures (Nakasone et al., 2006). Many aspects of beams with different form and material their geometric behavior, structural analysis (Both linear and non-linear), failure modes, elastic and plastic response under various loads and support have been successfully modeled using the finite-element method (Pasha et al., 2007; Queiroz et al., 2007; Al-Azzawi et al., 2010; Buyukkaragoz, 2010).

Finite Element Method (FEM) is a general purpose numerical method that has been developed with the development of computers and it is based on modeling a complete structure as a geometric mesh of elements, mutually interconnected which enables complex structural analysis. Applications range from the stress analysis of solids to the solution of acoustic and electromagnetic phenomena, neutron physics and fluid dynamic problems. Indeed the FEM is now established as a general numerical method for the solution of partial differential equations subject to known boundary and initial conditions (Nakasone et al., 2006; Jaini, 2008).

In this study, simply supported steel flat bars (As an example of beams) have been modeled using the commercial finite-element software ANSYS (Lawrence, 2005). The proposed model could simulate very well the maximum deflection of the bars subjected to concentrated loads applied at the center of the bars. The results of the modeling were compared with experiments performed with simple university-level laboratory equipment and the elementary beam theory.

Elementary Beam theory: For a beam with length of span L, uniform cross section i.e., constant flexural rigidity EI $(\mathrm{E}=$ Modulus of elasticity, $\mathrm{I}=$ Moment of inertia) simply supported and subjected to a central concentrated static load $\mathrm{F}$, the maximum deflection according to the elementary beam theory is (Hearn, 2000):

$$
\delta_{\mathrm{m}}=\frac{\mathrm{F} \cdot \mathrm{L}^{3}}{48 \cdot \mathrm{E} \cdot \mathrm{I}}
$$

For a beam with the rectangular cross section with width a and thickness $b$ as were the samples investigated in this research, the moment of inertia is $I=(1 / 12) \mathrm{ab}^{3}$. Thus for this type of beams the maximum deflection is:

$$
\delta_{\mathrm{m}}=\frac{\mathrm{F} \cdot \mathrm{L}^{3}}{4 \cdot \mathrm{E} \cdot \mathrm{a} \cdot \mathrm{b}^{3}}
$$

\section{MATERIALS AND METHODS}

Experimental detail: The apparatus used to perform the experiments was Modulus of Elasticity Apparatus from PHYWE SYSTEME GmbH. The setup of the apparatus is shown in Fig. 1. The dial gauge was mounted on the knife edge with stirr up. The flat bars have been positioned on the two supporting knife edges having the possibility to move in $\mathrm{x}$ and $\mathrm{y}$ direction. The geometric data of the setup

Corresponding Author: Naim Syla, Department of Physics, Faculty of Natural Sciences, University of Prishtina, Mother Theresa St. 5, 10000 Prishtina, Republic of Kosovo 

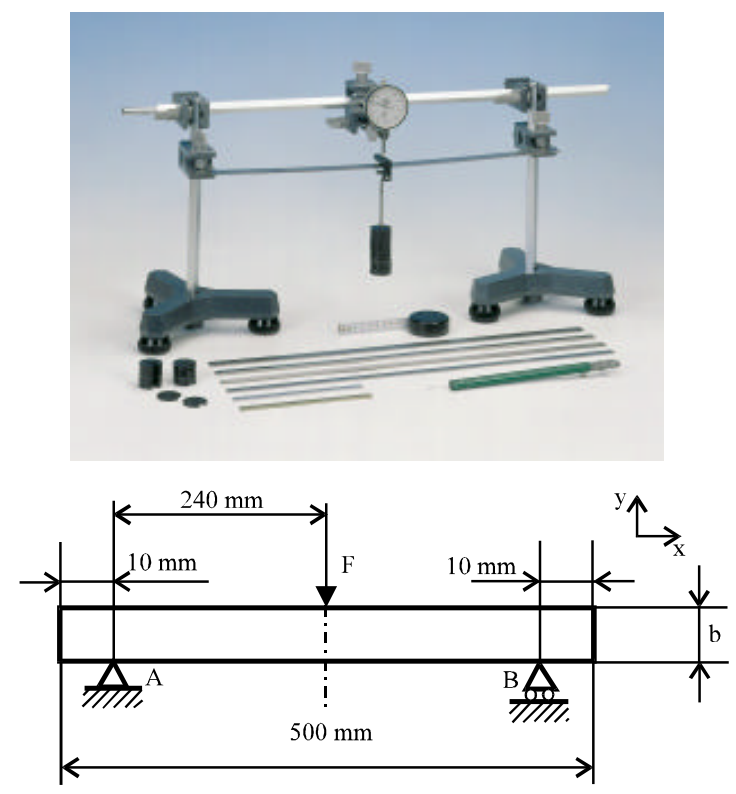

Fig. 1: a) Experimental set-up for determining the total bending of simply supported steel flat bars as function of hanging weights (Taken from PHYWE manual), b) Geometric data of experimental set-up and flat bars (Nakasone et al., 2006)

Table 1: Sample number, modulus of elasticity $E$, length of span $L$ width and thickness of stele bars and area moment of inertia I

\begin{tabular}{lcccc}
\hline $\mathrm{E}\left(10^{-11} \mathrm{~N} \mathrm{~m}^{-2}\right)$ & $\mathrm{L}\left(10^{-3} \mathrm{~m}\right)$ & $\mathrm{a}\left(10^{-3} \mathrm{~m}\right)$ & $\mathrm{b}\left(10^{-3} \mathrm{~m}\right)$ & $\mathrm{I}\left(10^{-12} \mathrm{~m}^{4}\right)$ \\
\hline 2.1 & 480 & 15 & 1.5 & 4.219 \\
2.1 & 480 & 10 & 1.5 & 2.813 \\
2.1 & 480 & 10 & 2.0 & 6.667 \\
2.1 & 480 & 10 & 3.0 & 22.500 \\
\hline
\end{tabular}

and the bars have been recorded several times or at different positions ( $\mathrm{PHYWE}, 2009$ ). The bars have the same length of span $\mathrm{L}$ but different cross section (Table 1). Coordinate system was positioned such that the $\mathrm{x}$-axis is in the direction of the longest dimension i.e., bars span; the $z$-axis in the direction of width and y-axis in the direction of thickness i.e., applied load. The bars are simply supported at points $\mathrm{A}$ and $\mathrm{B}$ and loaded by a downward concentrated static load of magnitude $\mathrm{F}$ applied at the center of the bars (Fig. 1b).

Dial gauge calibration: As the dial gauge possesses a restoring force which obeys Hook's law its characteristic curve has been determined as described in apparatuses manual (PHYWE, 2009). Figure 2 shows the calibration curve of the dial gauge. During experimentation the forces have been corrected accordingly for the resulting force of the dial gauge $F_{r}$. Hence, the effective force is the sum of the weights of the additional masses and the resulting

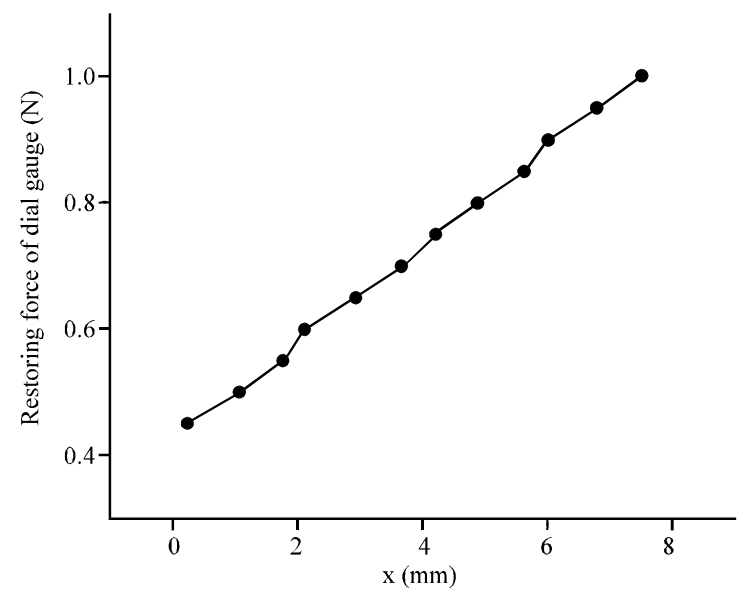

Fig. 2: Calibration curve of the dial gauge

force of the dial gauge, $F=m g+F_{r}$. The dial gauge is a complex mechanical device that sometimes shows high intrinsic friction. It manifests itself as an apparent nonreaction to changes. This problem can be resolved with gentle patting of the table where the apparatus is placed.

Modeling detail: The flat steel bars experimentally investigated were also modeled using FEM and the program of choice to implement the model was a commercial finite-element software ANSYS. This software offers a wide range of options regarding element types, material behavior and numerical solution controls as well as graphic user interfaces, auto-meshers and sophisticated post-processors and plotting capability to speed the analyses (Queiroz et al., 2007). As a finiteelement from the ANSYS library the element BEAM3 (Beam 2D elastic) was chosen. This element has three degrees of freedom (Translation along $\mathrm{x}$ and $\mathrm{y}$ and rotation about the $\mathrm{z}$ axis). The span of bars was meshed in 8 units or finite elements and boundary conditions were placed at points of support (UX and UY at point $\mathrm{A}$ and UX at point B) the concentrated static load was placed at the center of the bars. The geometric data of bars, material data of steel (Density $=7850 \mathrm{~kg} \mathrm{~m}^{-3}$, elastic modulus $\mathrm{E}=$ $2.1 \times 10^{11} \mathrm{~N} \mathrm{~m}^{-2}$, Poisson's number $\mathrm{v}=0.3$ ) are entered in the model and the program calculates the intensity of the displacements through entire span of the samples i.e., displacement at each node.

\section{RESULTS AND DISCUSSION}

Figure 3 shows ANSYS nodal solution for sample 4, loaded with $250 \mathrm{~g}$ or an effective force of $2.994 \mathrm{~N}$. The maximum deflection is $0.00146 \mathrm{~m}$ or $1.46 \mathrm{~mm}$ which is equal to the value given by elementary beam theory and very close to the value obtained experimentally which is $1.50 \mathrm{~mm}$. 
Res. J. Applied Sci., 6 (6): 387-390, 2011

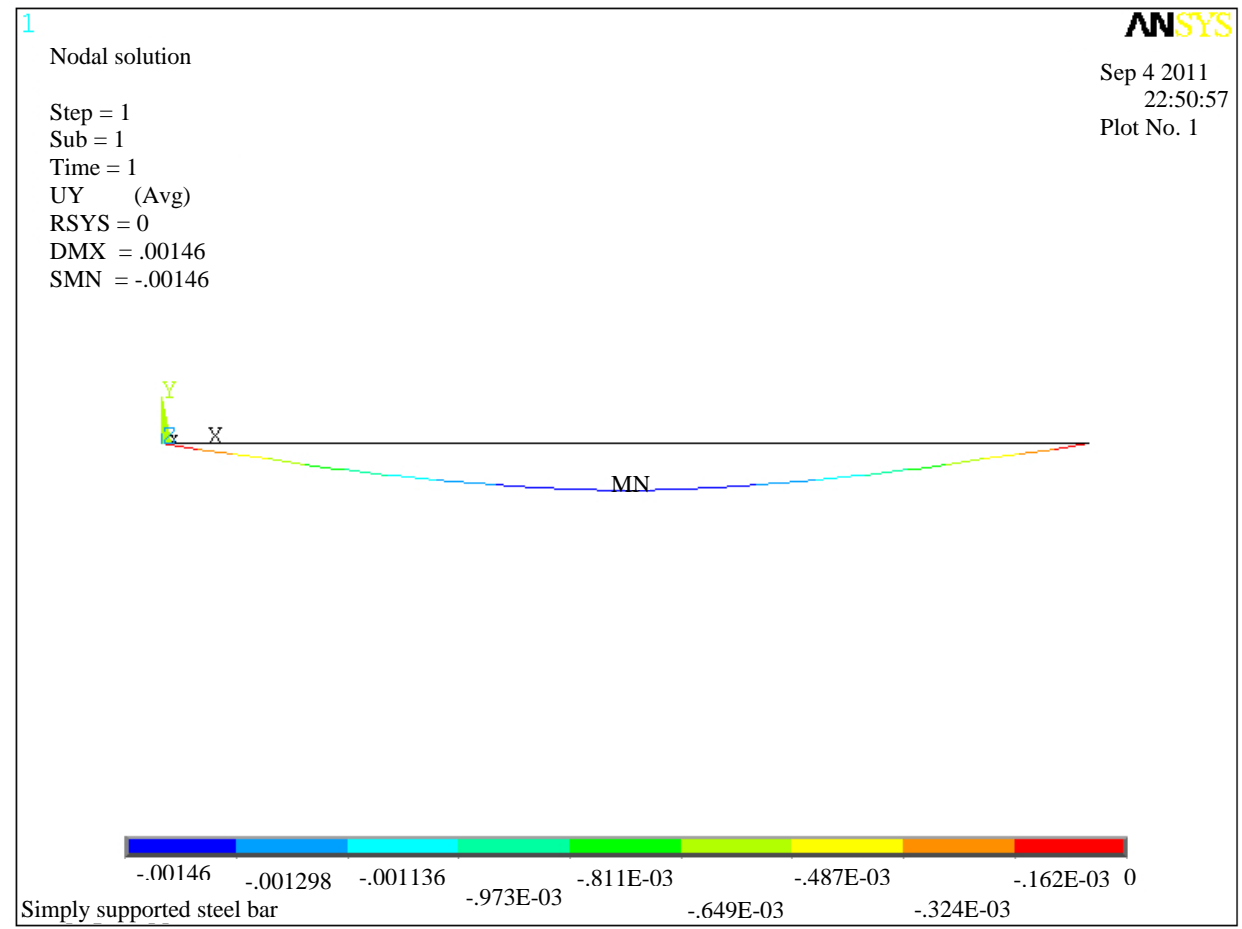

Fig. 3: ANSYS nodal solution for sample 4, loaded with 2.994 N. Similar graphs are obtained for other samples

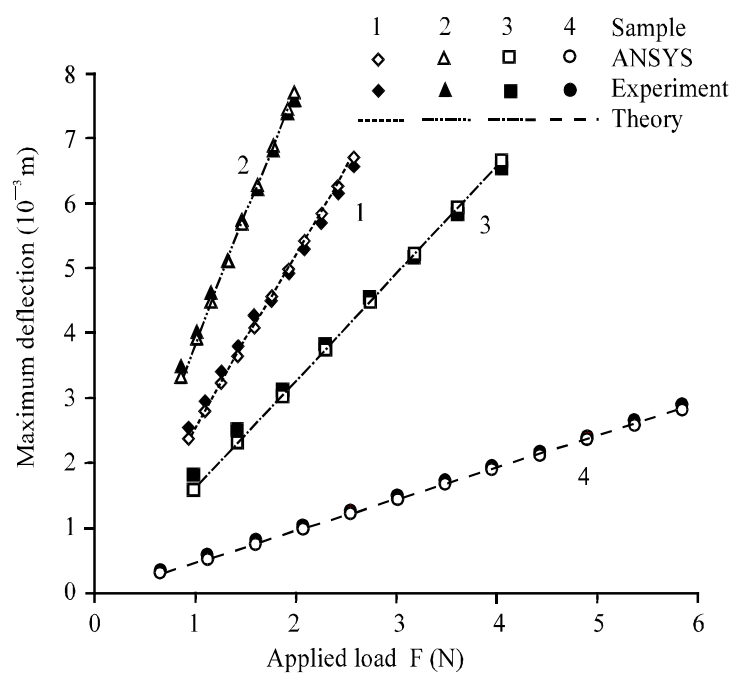

Fig. 4: Comparison of the results from ANSYS, elementary beam theory and experiments

Figure 4 compares the maximum deflection of the steel bars obtained by ANSYS with those by experiment and Elementary Beam theory. The results by three different methods agree well with one another. In one computes the slope of the least square fit of the maximum deflection on the applied load from the experimental data then given the geometric data of steel bars in meters it is possible to calculate the modulus of elasticity from the Eq. 3:

$$
E=\frac{10^{6} \cdot L^{3}}{4 \cdot \text { slope } \cdot a \cdot b^{3}}
$$

The values of modulus of elasticity calculated in this way are within $8 \%$ of the value given in literature $\left(2.1 \times 10^{11} \mathrm{~N} \mathrm{~m}^{-}\right)$. From the results shown in Fig. 4, researchers can conclude that the approach was correct. In principle, one can use the BEAM3 element to model the bending of the simply supported steel flat bars that are under a concentrated static load. This model can also be applied in cases when the load is dynamic a combination of uniform and static load and/or when the steel bars are clamped in one side (Cantilever beam). Simulation of the results in ANSYS is easy and straightforward. This model can help to confirm the theoretical calculations as well as to provide a valuable supplement to the laboratory investigations of behavior.

\section{CONCLUSION}

- Four flat steel bars with the same span but different cross section, simply supported and under a central concentrated static load have been modeled using a commercial finite-element software ANSYS; the results from FEM were compared with elementary beam theory and experiments performed with simple university-level equipment

- The results by three different methods agree very well with one another 
- The moduli of elasticity calculated from experimental data are within $8 \%$ of the value given in literature

\section{REFERENCES}

Al-Azzawi, A.A., A.H. Mahdy and O.S. Farhan, 2010. Finite element analysis of deep beams on nonlinear elastic foundations. J. Serbian Soc. Comput. Mech., 4: $13-42$.

Buyukkaragoz, A., 2010. Finite element analysis of the beam strengthened with prefabricated reinforced concrete plate. Sci. Res. Essays, 5: 533-544.

Hearn, E.J., 2000. Mechanics of Materials: An Introduction to the Mechanics of Elastic. Vol. 1, Pergamon, Oxford.
Jaini, Z.B.M., 2008. Crack chronology of reinforced concrete beam under impact loads. Master Thesis, Swansea University.

Lawrence, K.L., 2005. ANSYS Tutorial. Release 9. SDS Publication, Baton Rouge, LA.

Nakasone, Y., T.A. Stolarski and S. Yoshimoto, 2006. Engineering Analysis with ANSYS Software. Butterworth-Heinemann, Oxford, ISBN: 9780750668750, Pages: 456.

Pasha, R.A., Z. Suleman and M.Z. Klan, 2007. Analysis of thickness effect on piezoelectric beam. Department of Mechnical Engineering, FEMS, UET Taxila.

Queiroz, F.D., P.C.G.S. Vellasco and D.A. Nethercot, 2007. Finite element modeling of composite beams with full and partial shear connection. J. Construct. Steel Res., 63: 505-521. 